\title{
THE PARTIAL SUMS OF THE LEAST SQUARES RESIDUALS OF SPATIAL OBSERVATIONS SAMPLED ACCORDING TO A PROBABILITY MEASURE
}

\author{
WAYAN SOMAYASA \\ Department of Mathematics, Haluoleo University \\ Jl. H.E.A. Mokodompit no 1, Kendari 93232, Indonesia \\ w.somayasa@yahoo.com
}

\begin{abstract}
A functional central limit theorem for a sequence of partial sums processes of the least squares residuals of a spatial linear regression model in which the observations are sampled according to a probability measure is established. Under mild assumptions to the model, the limit of the sequence of the least squares residual partial sums processes is explicitly derived. It is shown that the limit process which is a function of the Brownian sheet depends on the regression functions and the probability measure under which the design is constructed. Several examples of the limit processes when the model is true are presented. Lower and upper bounds for boundary crossing probabilities of signal plus noise models when the noises come from the residual partial sums processes are also investigated.

Key words and Phrases: Least squares residuals, partial sums process, spatial linear regression model, standard Brownian sheet, Riemann-Stieltjes integral.
\end{abstract}

2000 Mathematics Subject Classification: 60F, 60G, 62G, 62J, 62K.

Received: 07-06-2012, revised: 07-01-2013, accepted: 16-01-2013. 